\title{
EXPERIMENTAL STUDY OF VERMICULITE INSULATED SAMPLES WITH CONVENTIONAL SAMPLES IN CONSTRUCTION INDUSTRY
}

\author{
Praveen Kumar E', Manojjkumar C ${ }^{2}$, Prakash K B ${ }^{3}$, Siddesh K Pai ${ }^{4}$ \\ ${ }^{1}$ Student of Post graduate program in Advance Construction Management @ National Institute of construction \\ Management \& Research (NICMAR) \\ ${ }^{2}$ Student of Post graduate program in Advance Construction Management @ National Institute of construction \\ Management \& Research (NICMAR) \\ ${ }^{3}$ Student of Post graduate program in Advance Construction Management @ National Institute of construction \\ Management \& Research (NICMAR) \\ ${ }^{4}$ Assistant professor - National Institute of construction Management \& Research (NICMAR)
}

\begin{abstract}
In the present study, exfoliated vermiculite is studied, it is used as a filler material because of its low bulk density, high refractoriness, low thermal conductivity and adequate chemical inertness. All along vermiculite has high amount of silica content. Thus effective utilisation of silica based materials as a building material. Presently, vermiculite is used for its light weight in the construction industry as a filler material above the deck slab. Experimentally some of cases are studied by using vermiculite in some of the applications in the construction industry. Case 1: One of the famous for tradition was originated in India at conventional tile which is especially designed for chettinad. Following some same methodology of the traditional tiles designed some of the mix proportions by increasing the usefulness of the tile. The tile which accepts the heat resisting parameters we designed the tile fulfilling the heat insulation property, flooring tile, roofing tile and as well as in weathering course tile replacing conventional weathering coarsee tiles. Various mixes were prepared using different percentage of vermiculite and water cement ratio. The developed vermiculite cement tiles exhibited low water absorption, better strength properties compared with the tradition famous conventional tiles used for flooring tile purpose. Thus it involve a continuous study and it combined by introducing the material which is suited for construction industry with vermiculite. Vermiculite insulated tile which is light in weight which is easy to handle. Designed some vermiculite mortar with various mix design ratios. Second case if it is implemented in concrete the strength parameters and some of the physical properties of the vermiculite insulated products. The special characteristics and usage of this material would decrease the structural weight can be decreased. Considering some other characteristics it is quite good material if it is replaced partial form gives better results.
\end{abstract}

Keywords: vermiculite concrete, lightweight, vermiculitetile, SEM, EDS. - ****

\section{INTRODUCTION}

Heat in building through roof is the major cause of unconditioned building or the major load for the air conditioned building. So we carried out the specific studies by comparing the two design methodologies in the same format in assigning the factors that would accept all the properties and statement. The designed mix and their following characteristics at different mix proportions are studied. Vermiculite is a inert material so to resist the heat penetration.

\section{Vermiculite:}

The name vermiculite is derived from a combination of the Latin word vermiculite are meaning "to breed worms," and the English suffix-ite, meaning mineral or rock. In its expanded form, vermiculite has a very low density and thermal conductivity, which makes it attractive for use as a soil amendment, lightweight construction aggregate, and thermal insulation filler.
Vermiculite is the geological name given to a group of hydrated laminar minerals which are aluminium-ironmagnesium silicates, resembling mica in appearance. It was incorporated into home insulation products branded Zonolite Attic Insulation in Canada and installed in hundreds of thousands of homes across the country. In fact, in the late 1970s and early 1980s, the federal government even offered a grant to people who installed products including Zonolite in their homes.[12]Various types in vermiculite: Crude vermiculite, palabora vermiculite, expanded vermiculite. Physical properties and chemical properties studies[11]The last process involved in the preparation of exfoliated vermiculite is called as the exfoliation.

\section{OBJECTIVE OF THE STUDY}

1. To study the properties of the vermiculite concrete with conventional concrete

2. To study the chemical composition of vermiculite insulated tiles by EDS analysis.

3. To comparatively study the particle settlement of vermiculite insulated tiles and conventional tiles by using SEM analysis. 
4. To comparatively study the ultrasonic pulse velocity test on the vermiculite insulated samples and conventional samples.

\section{LITERATURE REVIEW}

In order to reinforce wood-plastic composites (WPC)was used as reinforcing filler for WPC, so WPC/O-VMT composites were prepared. Characteristic morphologies, water absorptions and mechanical properties of the composites were investigated.[1].This work evaluates a novel bitumen modification through the use of expanded vermiculite (EVMt) which has been traditionally used as thermal insulation material[2]. The morphology of vermiculite samples was studied using scanning electron microscopy (SEM) and the changes of vermiculite structures were monitored using X-ray diffraction (XRD) analysis [3]. Fundamental knowledge of the dielectric properties of vermiculite, its interaction with electromagnetic fields and bulk materials handling technology was used to design and construct a continuous high throughput microwave processing system operating at $2.45 \mathrm{GHz}[4]$. The vermiculite/polyethylene nanocomposites were prepared with 7 mass $\%$ and 3.5 mass\% of vermiculite nanofillers using melt compounding procedure without additives [5]. . In order to obtain desired consistency, polymer admixtures such as SBR latex and super plasticizer (1 wt $\%$ of cement) was added in the mixes at 0.15 polymer cement ratio. Based on the test results, an optimum formulation was worked out for the vermiculite cement tiles on the basis of wettability of vermiculite surface and its proportion, vermiculite cement ratio and polymer-cement ratio a compressive strength in cement mortar cubes for 28 days for about 4.8 to $5.0 \mathrm{mpa}$ and a flexural strength of about 2.9 to $3.5 \mathrm{mpa}$.[6]. This paper, presents the results of an experimental investigation for a nondestructive test on real green ceramic tiles including manufacturing defects which will be reported in the research. [7]. Utilizing the dynamic Young's modulus of porcelain tiles, their firing strength estimated nondestructively. Additionally, measurement of ultrasonic velocity utilized to predict strength and dynamic Young's modulus of porcelain tiles. In addition, the two methods, used in measuring Young's modules, were compared. It was determined that the dynamic Young's modulus of porcelain tiles was greater than the static Young's modulus of porcelain tiles[8].

\section{EXPERIMENTAL CASE STUDY}

\subsection{Case 1: Vermiculite Insulated Tiles with}

\section{Conventional Tiles.}

Step By Step Process for Vermiculite Insulation Tile:

1.Tile is laid for $1.87 \mathrm{~cm}$ in thickness.

2. The tile has a length and breadth of $22.5 \times 22.5 \mathrm{~cm}$. Steel mould is prepared for the accurate size.Glassy surface is selected for pouring the pigment.

3. Pigment is selected as if necessary. Pigment preparation is certain while long process.

4. Pigment layer poured is layered with dry cement mortar $1: 3$.Third layer is poured and plastered with vermiculite cement mortar 1:3. 5. The process is next allowed to dry in sunlight for 7 hours and along with the glass it is immersed inside the water for curing. Curing is carried out for 7 days.Then dewatered and allowed to dry in sunlight. And then it is free to lay in floor. Vermiculite mortar contains a mixture of VM 1:3(1.75 parts of fine aggregate and 1.25 parts of vermiculite mixture with limestone, polypropylene fibres and admixtures).

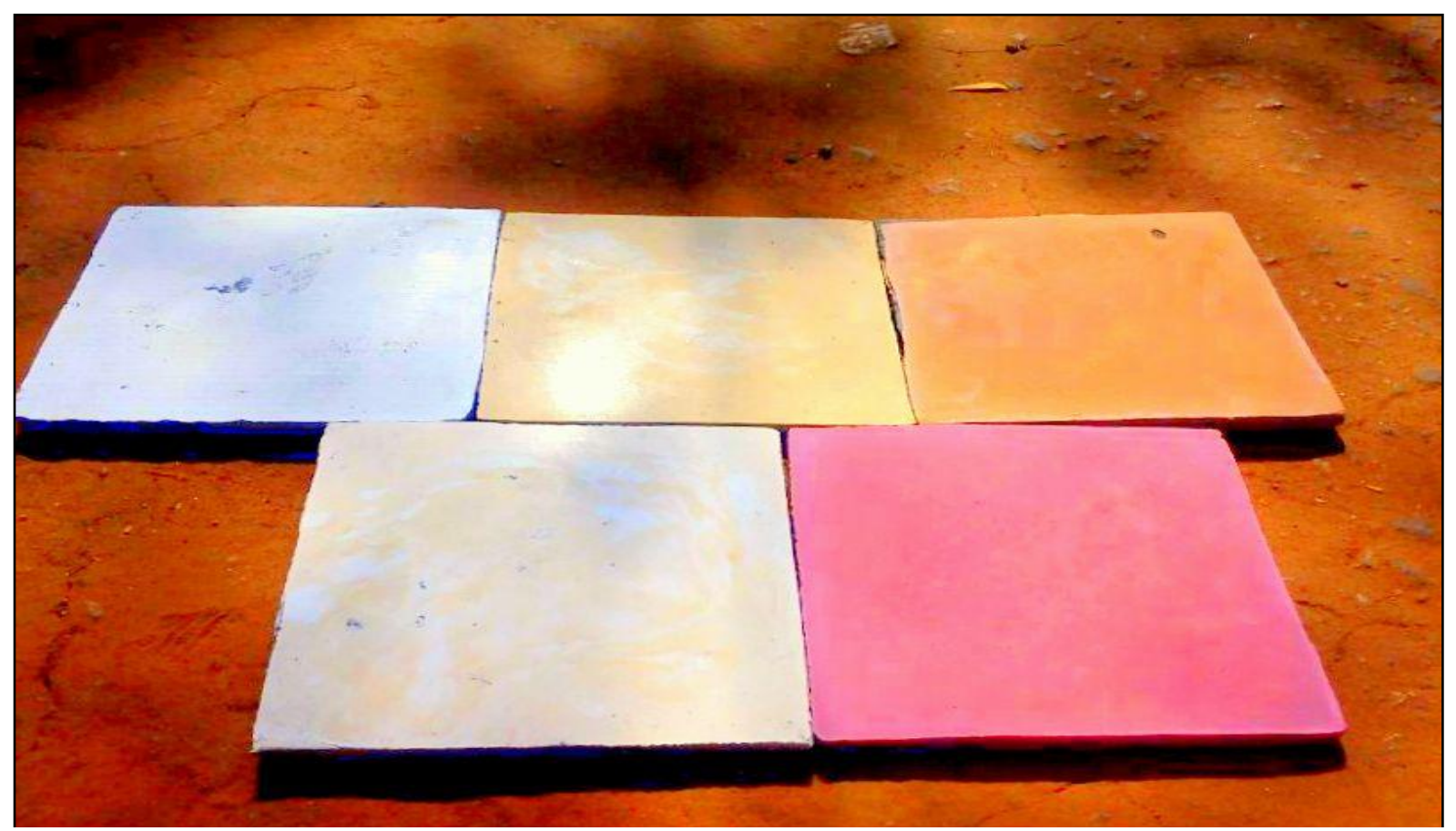

Fig 1: appearance of vermiculite insulation tile. 


\subsubsection{Results and Discussion}

\subsubsection{Scanning Electron Microscope:}

\section{Sample 1: conventional tile sample (VM 5) of $1 \mathrm{cu} \mathrm{cm}$.}
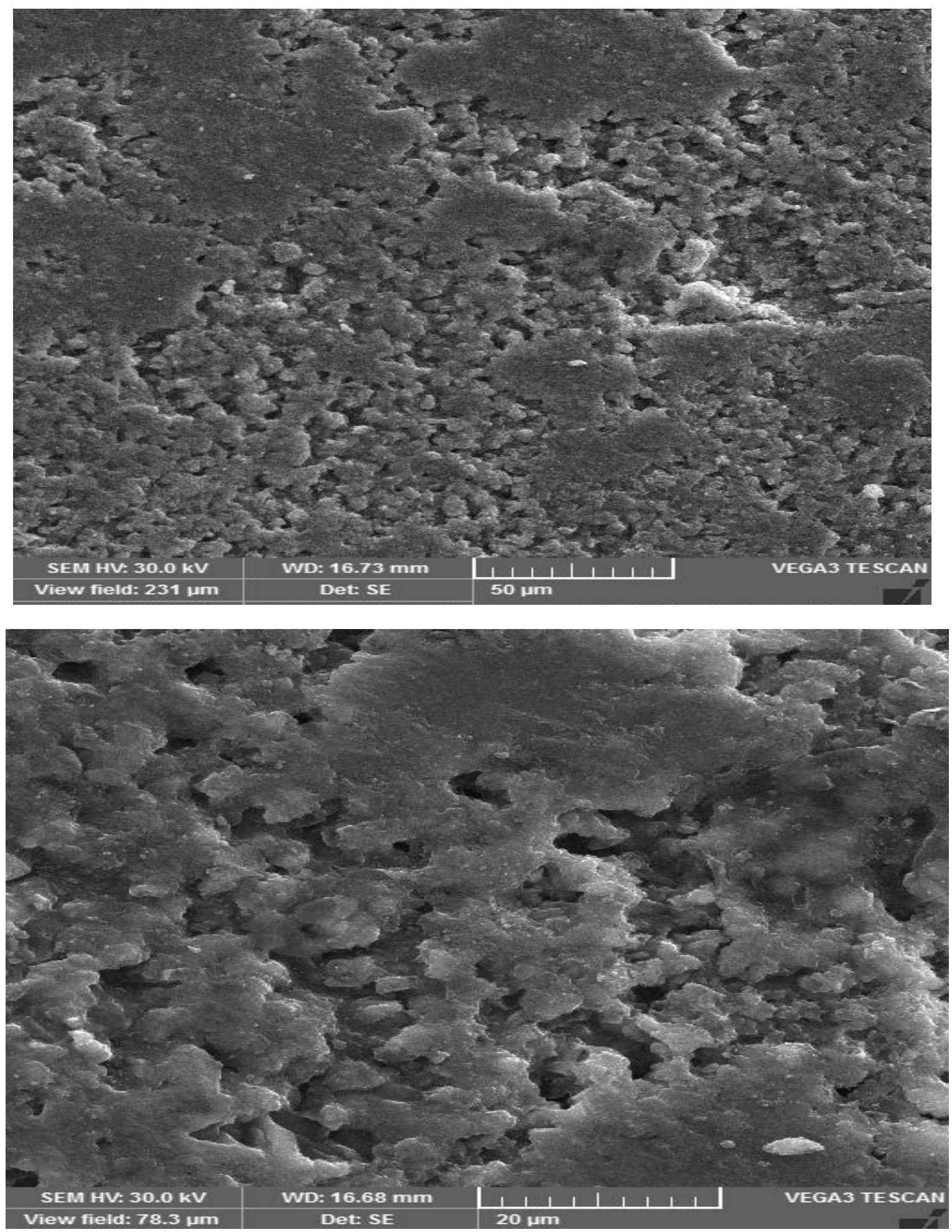

Fig 2: SEM images of conventional tile samples at $50 \mu$ and $20 \mu$ (laboratory test report:GRI,tamilnadu) 


\section{Sample 2 : vermiculite insulated tile sample (VM 5 ) of $1 \mathrm{cu} \mathrm{cm.}$}
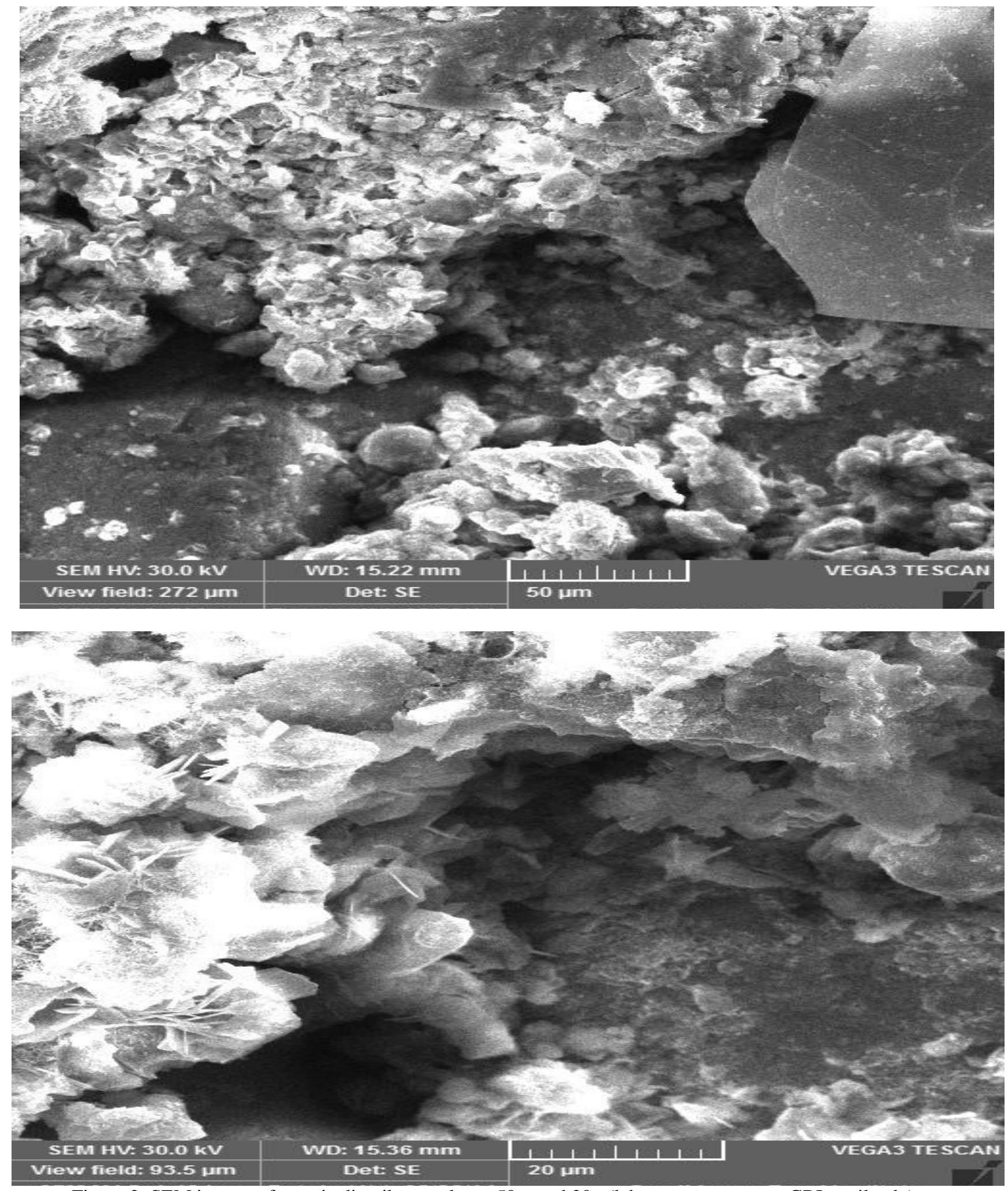

Figure 2: SEM images of vermiculite tile samples at $50 \mu$ and $20 \mu$ (laboratory test report:GRI,tamilnadu)

The images shows that the porous in the particle settlement should be minimised thus it provides a eco friendly nature in the samples. By observing the samples the voids in the samples while laying should be minimised while laying with proper mix and by adding superplasticers. Thus the surface layer compaction will be good.sample 1 shows a amphorphous surface. Whereas the sample 2 images are crystalline in structure. Thus sample 2 needs proper compaction and proper admixtures. 


\subsubsection{Electron Dispersive Analysis}

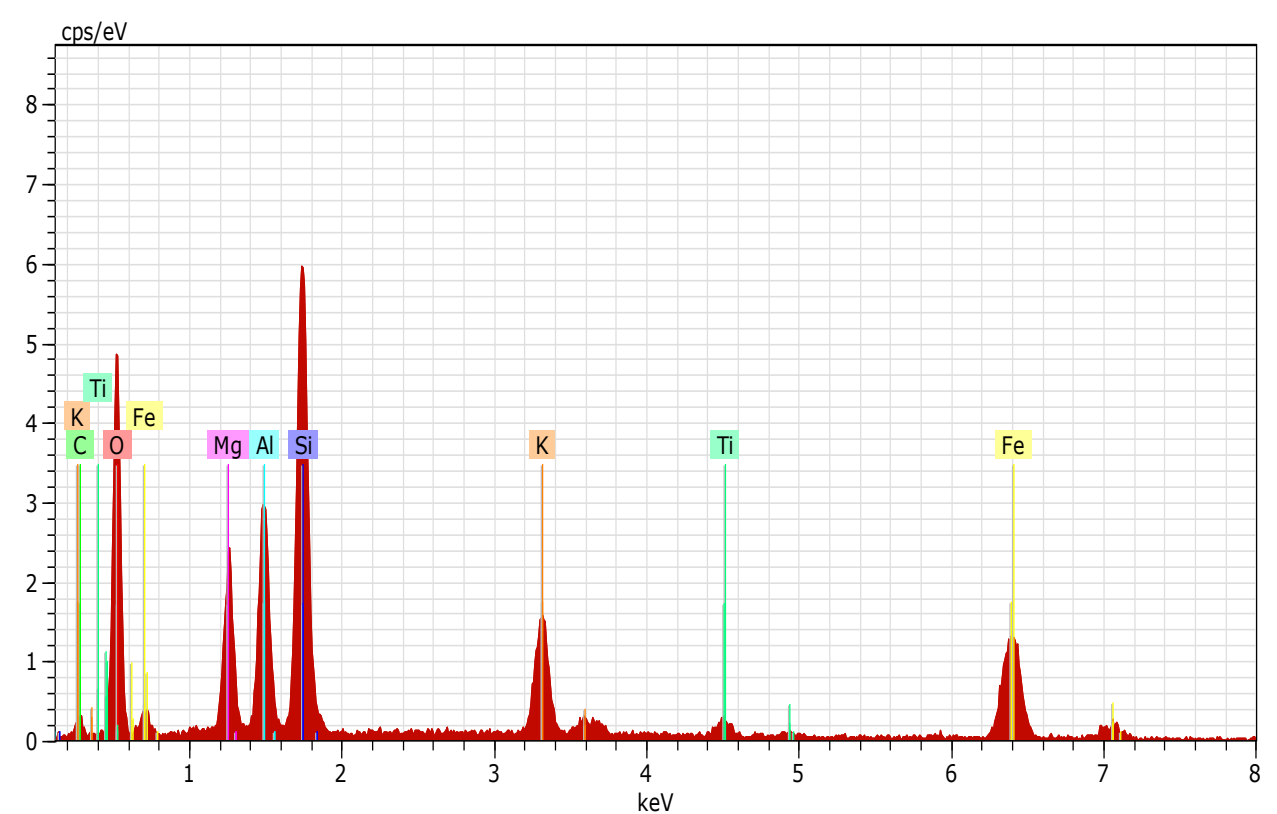

Fig 4: Electron dispersive analysis(laboratory test report:GRI,tamilnadu)

EDS provides chemical analysis of the field of view or spot analyses of minute particle more than 90 elements can be detected with our own atomic number detector using the EDSmethod. The chemical analysis method involve in non destructive test.

\subsubsection{Ultrasonic Pulse Velocity Test}

Ultrasonic Pulse Velocity testing of concrete is based on the pulse velocity method to provide information on the uniformity of concrete cement mortar, tiles, cavities, cracks and defects.Quality grading test to find the particle settlement without pores.

Table 1: UPV results as per IS 13311 (laboratory test report:GRI,tamilnadu)

\begin{tabular}{|c|c|c|c|c|}
\hline $\begin{array}{l}\text { SAMPLE } \\
\text { NAME }\end{array}$ & DISTANCE(MM & $\begin{array}{ll}\text { TIME(IN } & \text { MICRO } \\
\text { SECONDS) } & \end{array}$ & VELOCITY & $\begin{array}{lrl}\text { QUALITY } & \text { GRADING } & \text { (AS } \\
\text { PAER IS 13311 PART 1) } & \end{array}$ \\
\hline conventional tile & 22.5 & 6.64 & 3.38 & MEDIUM \\
\hline vermiculite tile & 22.5 & 6.88 & 3.27 & MEDIUM \\
\hline
\end{tabular}

\subsection{Case 2: Vermiculite Insulated Concrete}

\section{Step By Step ProcessFor Vermiculite Insulated concrete}

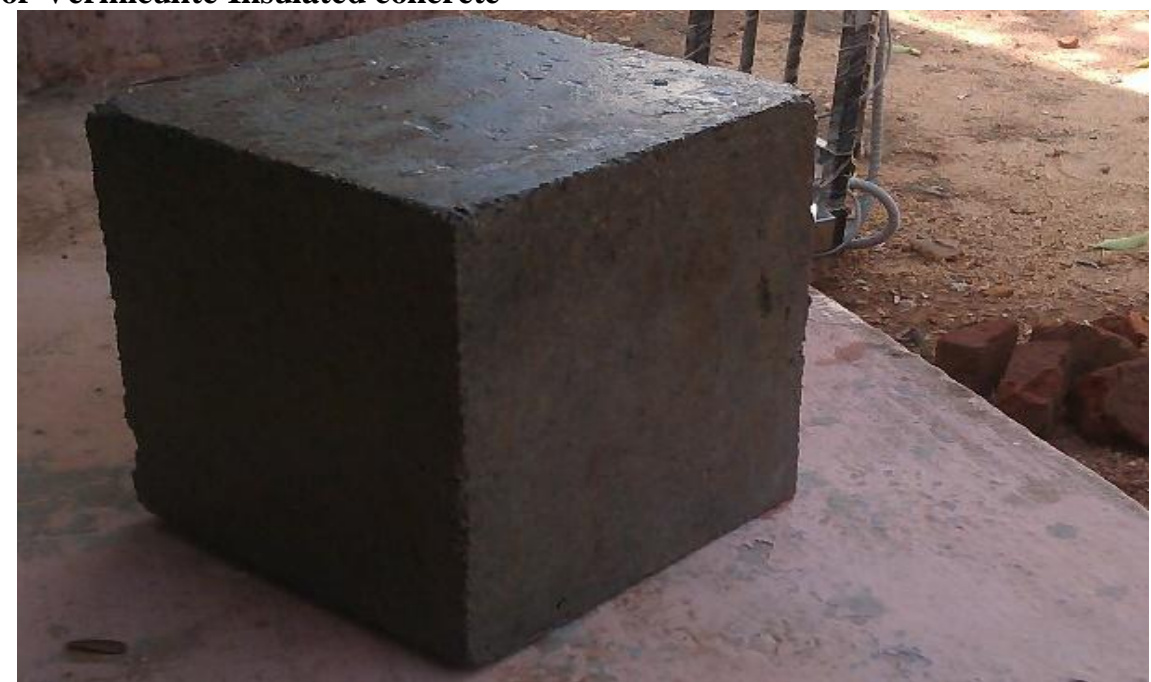

Fig 5: appearance of vermiculite insulated concrete. 
Vermiculite-1:6,1:8. Vermiculite is sevied as fine aggregate less than $4.75 \mathrm{~mm}$ fine particles. Its mixed with 1 part of cement as per the mixes given. Fine aggregate is replaced for $20 \%$ with exfoliated vermiculite. The concrete mix is prepared for M20, grade. Concrete is laid in a $15 \mathrm{~cm} \mathrm{X} 15 \mathrm{~cm}$ X $15 \mathrm{~cm}$ cube. Proper compaction should be given. Proper curing should be undertook, calculation of 7 days, 14 days , 28 day compressive strength. For getting more workability super plasticizers can be used like SBR latex, etc. Water cement ratio is calculated based upon IS10262.

\subsubsection{Results and Discussion}

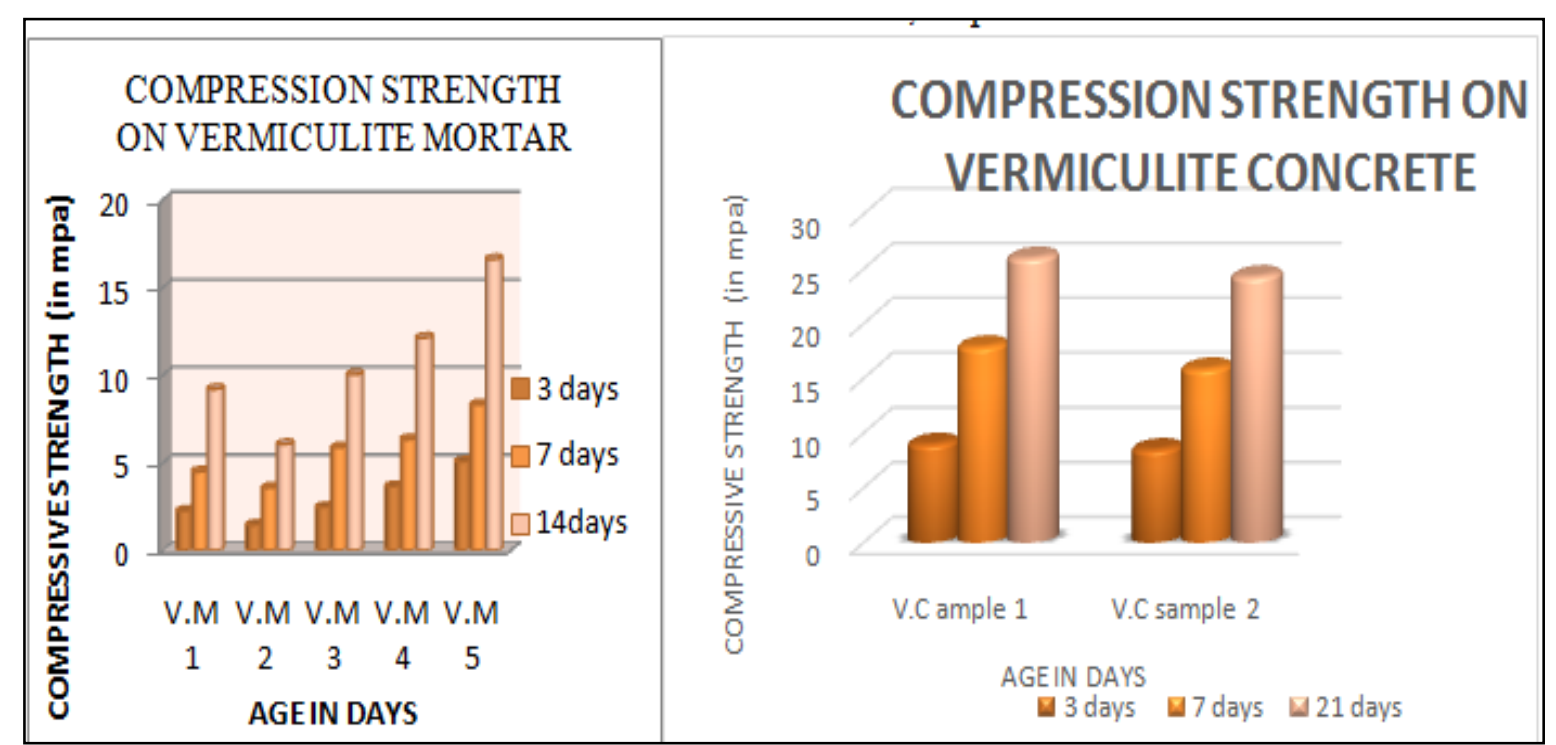

Chart 1: Compression Strength on Vermiculite Mortar

Chart 2: Compression Test On Vermiculite Concrete

For 20\% Replacement In FineAggregate .(laboratory test report:GRI,tamilnadu)

1. Compression test on cement mortar:Sample cubes are laid. Most of desirable characteristic properties of concrete are qualitatively related to its compressive strength. The apparatus used for the test is compression testing machine. This test is carried out in a $7.06 \mathrm{~cm}$ X $7.06 \mathrm{~cm}$ X $7.06 \mathrm{~cm}$ size cube, as per IS 516-1959. The results are chart 1

2. Compression test on cement concrete: The cubes laid on the $15 \mathrm{~cm} \times 15 \mathrm{~cm}$ x $15 \mathrm{~cm}$ size. Are taken for 3 dys, 7 days and 21days . Laboratory testing after proper curing obtained the results as shown in chart 2 . The cubes are laid in M20 grade concrete. The mixture obtained for $20 \%$ replacement attained good results.

3. Light weight concrete: Comparatively the weight of the concrete is much lesser than the conventional concrete. The weight of the conventional concrete will lie between 8.5 to $9.5 \mathrm{kgs}$. Thus the weight obtained for the vermiculite insulated concrete is less than $6 \mathrm{kgs}$. As shown in the figure.

\section{Light weight concrete}

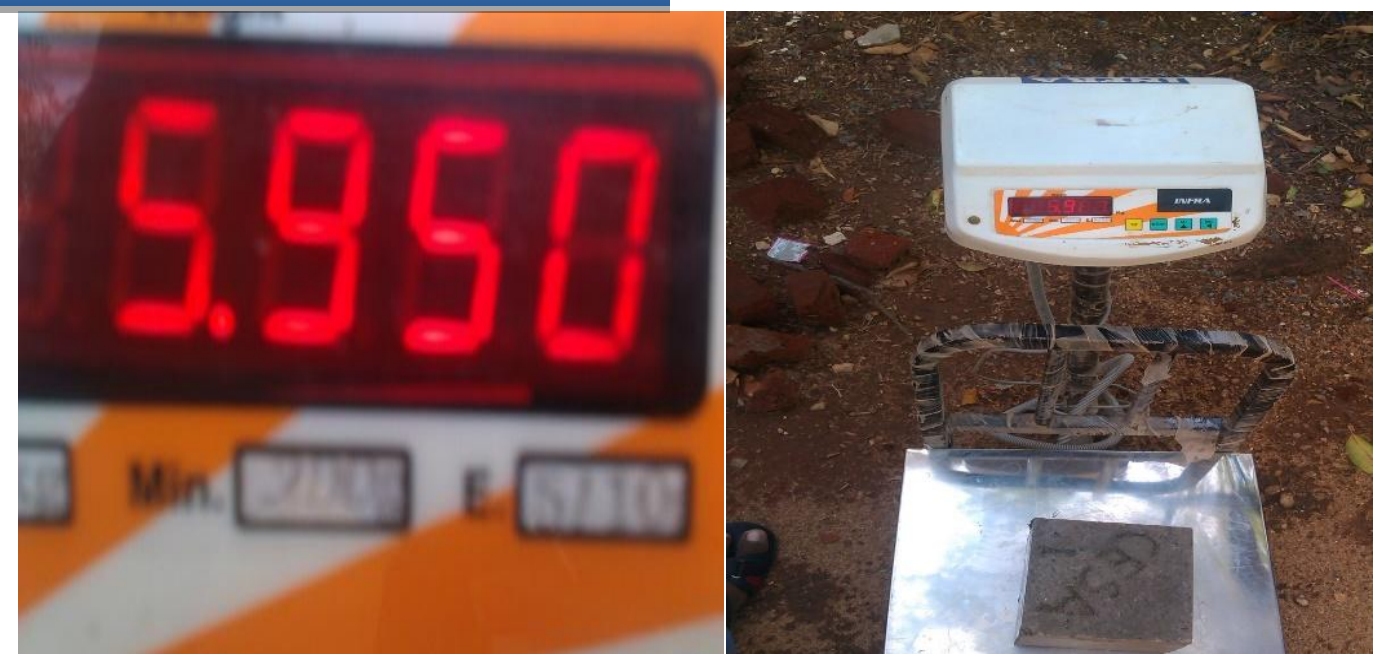

Fig 6: self weight of Vermiculite Concrete cube (light weight For 20\% Replacement In Fine Aggregate ) 


\section{BENEFITS OF TECHNOLOGY}

- The people below poverty line will live in single roofed building, it is quite uneconomical in usage of air conditions, in such condition it is economical in providing them with the vermiculite roofing. Vermiculite roofing's is much stronger and highly heat resistive. This can be also laid of the top floors as weathering coarse by mixing it with surki mortars, instead of limestone.

- It is totally economical to provide assistance to the villagers and mainly in the rural housing.

- If it is adopted in roof concrete as partial replacement also reduces the heat penetrating inside the building.

- On the top floor the roof can be provided with filler slab technologies could also minimize the cost. By implementing the vermiculite roof tiles as fillers.

- Many more research is under process for implementing these technologies in the normal building material

- About $40 \%$ of total weight of the concrete is reduced.

\section{RECOMMENDATIONS}

- It is necessary to study the strength parameters and flexural testing on the vermiculite insulation tile.

- To study the coefficient of thermal expansion and thermal conductivity of the vermiculite insulation tile with the proper laboratory setup.

- This study can be carried for long duration on heat resisting parameters.

- To study the durability parameter of the vermiculite insulated tile and vermiculite insulated concrete. And Implementation of vermiculite could result in energy efficient studies.

\section{CONCLUSION}

Vermiculite is a filler material used in the construction industry mainly for its low bulk density and inertness. Vermiculite is used for insulation property. Thus, the heat penetration and the heat resisting capacity of building increase only when this property induced in the preparation of tile. Thus good results are obtained in the vermiculite insulation tile samples although the thermal resistivity is 16.9 - $18.8 \mathrm{~m} . \mathrm{K} / \mathrm{W}$ from the article [20]. This material has good thermal resistivity so, Thermal resistivity property should be studied in the future. The case study 1 say that the vermiculite insulated tile compared with conventional tiles using sem analysis shows the particle settlement. The EDS analysis also the amount of silica content is so high that it is one best material that can be used for construction industry. The ultrasonic pulse velocity test is carried out that the samples are medium samples as per as IS 13311. So that the quality and particle settlement is compared. Case study 2 say that vermiculite has a good strength values when it is used along $20 \%$ along with fine aggregate using superplasticiers the workability will be easy. The bulk density of the particle is low it is identifies that the weight of the concrete is reduced upto $40 \%$ of its weight depending upon the mix proportions. In further the thermal resistivity and heat resistivity to be studied. Thus vermiculite can be used widely in construction industry as filler materials in various applications

\section{ACKNOWLEDGEMENTS}

Deep gratitude's to people who rendered their help throughout this project.

\section{REFERENCES:}

[1]. Xiang Li, Bingrong Lei, Zhidan Lin, Langhuan Huang, Shaozao Tan, Xiang Cai "The utilization of organic vermiculite to reinforce wood-plastic composites with higher flexural and tensile properties" Industrial Crops and Products, Volume 51, November 2013, Pages310-316.

[2]. Henglong Zhang, Hongbin $\mathrm{Xu}$, Xiaoliang Wang, Jianying $\mathrm{Yu}$ "Microstructures and thermal aging mechanism of expanded vermiculite modified bitumen" Construction and BuildingMaterials, Volume47, October2013, Pages919926.

[3]. Karla CechBarabaszova, Marta Valaskova "Characterization of vermiculite particles after different milling techniques“ Powder Technology, Volume 239, May 2013, Pages 277-283,

[4]. OlaosebikanFolorunso, Christopher Dodds, Georgios Dimitrakis, Samuel Kingman "Continuous energy efficient exfoliation of vermiculite through microwaveheating" .International Journal of Mineral Processing, Volumes 114117, 21 November 2012, $\quad$ Pages 69-79,

[5]. Marta Valaskova, Jonas Tokarsky, Karla CechBarabaszova, VlastimilMatejka, Marianna Hundakova, Erich Pazdziora, DusanKimmer"New aspects on vermiculite filler in polyethylene "Applied Clay Science, Volume 72, February 2013, Pages 110-116,

[6]. Rajini Lakhani, SpAgharwal, SapnaGhai\&R.K.Saxena "vermiculite cement mortar for thermal insulation", CSIR, Roorkee 247667 (UK),December 2013

[7]. Elbehiery, H.M. ; Hefnawy, A.A. ; Elewa, M.T.'Quality control enhancement via non destructive testing for green ceramic tiles" Circuits and Systems, 2003 IEEE 46th Midwest Symposium on 3 DOI:10.1109/MWSCAS.2003.1562492 Publication Year: 2003 , Page(s): 1130 - 1133 Vol. 3 .

[8]. Eliferen, Semrakurama "Characterization of Mechanical Properties of Porcelain Tile Using Ultrasonics"Anadolu university, department of materials science and engineering, 26555, eskisehir, turkeyreceived: 01.03.2012 accepted:07.03.2012

[9]. Artisians In Architecture "Material Study On Conventional Tile" study more on http://www.prismma.in/crafts-of-india-conventional-tiles/, study more on http://www.livemint.com/r/LiveMint/Period1/oldpdf/2b0f40 30-6f9e-4d02-bd27 33546773293e.pdf 
[10]. Hellier, C.J., "Handbook of Nondestructive Evaluation”, Mc Grow-Hill, New York, 1.1, (2001).

[11]. Dupré Minerals Ltd.Spencroft Road, Newcastle-underLyme, Staffordshire ST5 9JE, England Website: http://www.dupreminerals.com

[12]. Kulkarni, N., Moudgil, B., Bhardwaj, M., "Ultrasonic Characterization of Green and Sintered Ceramics" I, Time Domain", American CeramicSociety Bulletin, 73(7): 146153, (1994).

[13]. Medding, J.A., "Nondestructive Evaluation of Zirconium Phosphate Bonded Silicon Radomes", Phd. Thesis, Virginia Polytechnic Institute andState University, Virginia, 43, (1996).

[14]. "The Vermiculite Association" Kingsley House, Ganders Business Park, Kingsley, 